\title{
The Role of Graphic Organisers in Learning and Teaching
}

DOI: 10.47050/66515321.170-184

Marine H. Arakelyan

This chapter aims to describe the significance of various graphic organisers not only in teaching but also in learning cycles across the course continuum. They are effective instructional tools to enhance students' creativity, innovative mindset and higher-level thinking and to integrate previously-acquired knowledge with the existing proportion of the learnt schemata. Moreover, the implementation of different graphic organisers as useful visual tools in different modes, at various levels, and across all skills and subject domains fosters active learning and effective teaching under different circumstances to identify alternative learning opportunities and achieve various accessible and measurable learning outcomes as an integral part of the curriculum. The chapter also reveals not only the advantages of graphic organisers' incorporation into our teaching and learning phases, but also possible disadvantages that might occur while graphic organisers are used in a learning task.

In this paper, a further effort is made to illustrate the impact and importance of e-portfolio implementation as an interactive and effective device containing multiple graphic organisers to foster learning/ teaching styles and strategies, reflection, and awareness in both teachers and students.

\section{Keywords:}

visual, self-awareness

enhance, comprehension

higher-level thinking 


\section{Introduction}

In all stages of language learning, the process is presented as a multilayered, continuous and interesting procedure. This paper is aimed at illustrating the value of various graphic organisers in teaching and learning cycles across the course continuum as effective instructional tools. There is no doubt that these powerful tools assist students with realising their departure point before starting their learning journey through the content, where they are at that specific moment and where they are planning to reach (Boudah, Lenz, Bulgren, Schumaker \& Deshler, 2000).

As useful teaching tools, they can be used for all types of students (e.g. mixed-ability classes, gifted students or those with special needs) in all stages of the learning process and within every discipline (EFL, Social Studies, Math, Research, IT, Assessment, etc.).

According to Gallavan and Kottler (2007), graphic organisers are practical methods of great importance because a large proportion of information can be simplified as per the requirements and the students' level and presented by serving multiple curriculum-oriented purposes from different perspectives.

This makes learning a more manageable, meaningful, achievable and enjoyable task, especially for students with special needs (Gallavan \& Kottler, 2007). The above-stated features have a clear connection with the ones that have been determined, revealed and demonstrated in various settings throughout my learning/teaching experiences.

\section{The Importance of Sharing Experiences}

For today's classroom, the incorporation of graphic organisers as a set of different teaching techniques and strategies and as effective learning tools provides students with more control over the content with all its components within a learning task and facilitates both their understanding of the assigned activities, their own learning styles and modes and their awareness of their inner strengths and weaknesses.

The effective use of these tools also assumes to foster students' ownership of the presented information and their active involvement in all cycles of an acquisition process where students internalise what they are learning with all the connections between the concepts and paths, sometimes adjusting them to their own ways of perception and emphasising the most significant parts of the provided information in a brief and logical order (Bromley, DeVitis \& Modlo, 1995). 
In the meantime, teachers should take into account the need for differentiating their teaching strategies and the ways and methods of how to implement graphic organisers not only for language teaching and learning but also for enhancing higher-order thinking skills. It is obvious that the use of graphic organisers in any phase of a learning or teaching cycle can have a positive backwash effect on students' active engagement and comprehension. This will lead to a productive phase of student-student and teacher-student interactions where all the participants are involved in meaningful and purposeful learning. Thus, according to various researchers (Hutchinson, 2007; William, 2005), the effective use of graphic organisers positively impacts and enhances all strata of students' active learning processes and academic performance, including students with learning disabilities.

\section{Applications of Different Graphic Organisers}

Various phases of any learning cycle take time, as students mainly perceive new elements of knowledge by questioning the known and the unknown and observing multifaceted components of authentic information embedded into in-class and out-of-class learning tasks.

It is assumed that in order to understand newly-formulated information throughout a learning cycle, either the information must be broken down into manageable and achievable chunks so that students can easily spot and infer, even indirectly, stated relationships between the separate ideas, or it must be organised to filter core pieces of information, based on which any student can align the associated concepts/ideas with their background schemata.

Hence, being universal in nature, graphic organisers appear to be valuable devices that facilitate the comprehension of various instructions, make the invisible meanings of the concepts visible and enhance student learning no matter the extent of the students' cognitive maturity, types of learning styles and strategies, or prior experience of their engagement in the learning cycle. Moreover, it is believed that students should feel free to experiment and take risks while increasing their ability to think and to take responsibility for their own learning. Thus, being powerful tools, once teachers use graphic organisers in any phase of instruction, it is inevitable that students' learning will improve (Hall \& Strangman, 2002). It should be noted at this point that even though different terminology is used, such as story, concept or mind 
maps, cognitive and advanced organisers or concept diagrams, they will all be referred to here as graphic organisers.

To get the whole picture, it is essential to mention that there are many ways to classify graphic organisers. As stated by Bromley et al. (1995), graphic organisers are classified into four basic types, based on how the represented information is arranged. However, regardless of the chosen method of representation, graphic organisers are considered to be more effectively implemented and better instructional tools if they are clear and straightforward with plain instructions focusing only on the core information (Boyle \& Yeager, 1997; Egan, 1999). More specifically, the first of the categories is called cyclical as it displays the sequence of events or organises numerous pieces of information in a process without stating the exact beginning and ending. The second category is called conceptual, due to the fact that it indicates how a core concept is supported by relevant facts, evidence and characteristic features. The third type is known as sequential. It shows the relationship between an essential concept and sublevels of the features such as cause-effect and problem-solution.

Hierarchical organisers belong to the fourth category. They may be especially useful tools when the students' aim is to perceive the relationships between diverse parallel ideas and their relationship with a larger concept or an idea as well as the chronological order of different events within the timeframe. They also help students to correctly keep track of details, activate their prior perception(s) of the concept and prevent them from the confusion of which details are associated with which main idea. Thus, various types of graphic organisers within each of the above-mentioned categories such as Venn diagrams, fishbone maps, flowcharts, timelines, rubrics, spider maps, and matrices can illustrate both simple and complex information based on either a single concept or multiple/parallel concepts.

It is very likely that the integration of various organisers into learning enables students to create semantic maps and story maps to facilitate and enhance reading comprehension (Hutchinson, 2007). Moreover, the incorporation of graphic organisers into learning enables students to develop concept-associated structures, store newly-perceived pieces of information and align them with previously-gained schemata for comprehension and assessment purposes that emphasize a stronger sense of ownership of their own work. 
In the meantime, teachers elaborate new graphic organisers to evaluate students' understanding of the provided information (Hutchinson, 2007) for research projects or other specific learning tasks for which the purpose, assessment type and learning outcomes to be met are clearly stated. These tools facilitate both student-guided and independent learning through active interaction and meaningful learning where students pose thoughtful questions in order to arrange, comprehend, retain and internalise new pieces of information for further use (McKnight, 2010; Hutchinson, 2007).

Needless to say, this will foster students' higher-order thinking, such as critical and analytical thinking skills, which will make them more successful and independent learners. Furthermore, while using cause-effect, KWL, web clusters, compare-contrast, Venn diagrams and other thought-provoking graphic organisers, students become capable of visualising general concepts and breaking them down into manageable, meaningful and specific ideas that will push them a step closer to becoming better decision makers and problem solvers, triggering other soft skills into their everyday life. Hence, the various applications of graphic organisers across different subject areas, skills and levels create a positive backwash effect on student-teacher and student-student interactions, leading to the enhancement of students' learning.

During teaching/learning cycles, due to the multiple advantages of these instructional tools, they can be used within any stage of a planned lesson and in various ways (as a warm-up activity to generate ideas or a wrap-up), based on the purpose of the lesson and the learning outcomes required to be achieved by its end. More specifically, they can be used across language and content area acquisition stages not only individually but also in large groups. It has been described (Merkley \& Jeffries, 2000) that, through these effective devices, teacher-directed instruction is transformed into student-directed instruction where the emphasis is on students' metacognitive skills in general that can be used in different situations.

Ellis (2004) suggested a number of steps to follow. First, the teachers should explain to students exactly how the organiser is used and what is required to be done, and allow the students to create their own graphic organisers by focusing only on essential information. In this way, the teachers will facilitate students' learning on both how content 
is organised and how graphics work in the domain of visual strategies. Afterward, modeling can be taken on board to reveal all the challenges and subtleties of how to implement the preferred method, which will be followed by guided practice.

In light of this, both the teacher and students can come up with many possible ideas on how to complete the graphic organiser meaningfully and purposefully as an overall class objective. There can also be small group practice, where the students may learn from their peers through observing other effective and interactive approaches to the same procedure. Moreover, students may be assigned some thought-provoking tasks on graphic organisers in groups to trigger their accountability for a better result as well as strengthen their communication skills. Finally, students can deal with the organiser by themselves, but they should be given support and constructive feedback if necessary.

All these steps will make students more confident in getting enrolled in independent practice and using various graphic organisers. As soon as the students master the skill and perceive the whole array of the usage of these tools, they will generate their own graphic organisers, web clusters, diagrams and concept/mind maps. Though students will have independence in creating and completing graphic organisers, the teacher must follow this sequence for each type or format introduced and encourage the students to reveal the relationships between the ideas/concepts and identify the information contained and the learning outcome behind the task.

Each of the above-enumerated components can be incorporated into teaching and learning practices across all the areas of the EFL setting. Thus, depending on the objectives of the class, the teacher's goal for a specific lesson and its nature, and the learning styles of the students engaged, the application of graphic organisers can be different: to write an essay or reports, to prepare briefs and outlines, to take notes on major issues or main ideas from lectures or internet sources, to make an outline for project work or a planned presentation, or to organise relevant information to study for an exam or for a graded-reader book review.

It is worth stating that these various skill-oriented graphic organisers are considered to be powerful instructional tools that make student learning more enjoyable, meaningful, and sustainable. Moreover, due 
to the above-mentioned reasons, the scope of graphic organiser-related research still remains an ongoing path of inquiry for various scholars.

Another important thing to note is that when students are given flexibility and clarification on the purposeful and meaningful use of graphic organisers, they can use numerous graphic organisers corresponding to their learning styles, needs and levels of intelligence. In addition, there is tangible evidence of the positive influence of graphic organisers on students' better comprehension of a large chunk of new information and completion of complex tasks (Ellis, 2004).

As a result, students are able to generate concept-associated structures or create images in their minds to uncover multilayered aspects of the content, store newly-acquired information in their long-term memory, align it with previously-obtained knowledge, reveal conceptual relationships, graphically depict the overall representation of similarities and differences, causes and effects, problems and solutions, and discuss and evaluate relevant relationships between content and sub-content, main idea and supporting details (McKnight, 2010).

\section{Challenges with Graphic Organisers}

There may be a number of challenges while finding out the most effective ways of implementing graphic organisers across skills, levels and subject domains. It is obvious that graphic organisers must not be overused since the students may become stressed or bored because the process of graphic organiser completion can be time-consuming and may negatively impact students' creativity.

It should be said that not enough research has been done with detailed investigations on the types of graphic organisers to be incorporated in overall comprehension, specifically in the reading dimension, and the type of students who benefit most from the specific use of these visual devices. This means that in some situations, possible drawbacks might occur while incorporating graphic organisers in a learning task. For example, note-taking may decrease when students learn new material by applying graphic representations. Consequently, students may lack a comprehensive guide while revising the material, which may affect their academic performance.

Another shortcoming is closely related to giving constructive feedback on a particular task or situation-related graphic organiser. 
Creating some criteria or a rubric to assess graphic organiser completion is supposed to be time-consuming. Teachers mostly implement graphic organisers to foster brainstorming, discussions, explanations of complex ideas, and active engagement. However, they do not tend to make corrections and give comments on each student's organiser when it is complete. As a result, the student may miss out on the chance to receive valuable feedback.

Being teachers, we always plan our lessons with the intention to maximise student engagement in the class, make it interesting and interactive, and achieve the learning outcome(s) by the end of the class. As the teacher has the needed flexibility to flow from one topic to the next and can answer questions, this may lead students to another part of the context in different domains of teaching and learning.

In addition, when the class teachers use graphic organisers as a review tool, they are of great significance, as they help students recall important facts on various features and concepts. On the other hand, arranging information from a written text, an audio conversation, a lecture or a writing prompt on an organiser, such as a Venn diagram, can allow students to visualise how something is similar, different or the same. They can see all this information on one sheet of paper so they do not need to take pages of notes to study at home, making it less frustrating and confusing.

According to Drapeau (2009), graphic organisers are instructional tools that can be implemented for all types of students in all phases of the learning and teaching process. Thus, the use of these effective tools will foster the methods of students' creativity and develop more meaningful and active learning experiences at various stages of the learning cycle, accompanied by higher-order competencies.

All in all, there is no single technique or approach that can be applicable to every student. Therefore, the maximum level of acquisition can only be derived if teachers are well equipped with the ability to use the strategy in an appropriate way, typical of the level of the students' proficiency.

\section{Interaction through Graphic Organisers}

The use of different types of graphic organisers in the EFL setting can effectively contribute to the creation of a wider learning/communicative environment in which the students are encouraged to reveal their 
competences, enrich their English vocabulary, acquire English language skills and unfold their self-concept in an interactive way. The employment of the best practices of gained knowledge construction, vocabulary improvement, structured information creation, story demonstration, essay writing and other techniques is designed to prove that students are given the opportunity to interact not only with each other and with the teacher, but also with the given content or information with the explicit intention of decoding all the aspects of the concept or content.

In terms of the advantages of different applications of graphic organisers, it is worth mentioning that they can be used in numerous ways to improve the overall comprehension of EFL learning skills, which makes them challenging and primary tools in all EFL classrooms.

One of these helpful visual tools is concept maps, which permit students to concentrate on the exact concepts essential to boosting meaningful learning cycles and thorough comprehension. According to Cesarone, a concept map is a "chart-based graphic that describes a concept and its various relationships, with general concepts at the top, supporting concepts at the bottom, and lines showing the connections between the concepts" (2007, p. 191).

This approach enables students to elaborate a new proportion of information to the existing schema. It is undeniable that the students will then have ample practice in the basic skills required to master verbal and written English. Cesarone (2007) suggested that concept maps could be implemented to foster the overall comprehension of the students with learning disabilities, as these students encounter enormous hardship in expressing themselves and connecting ideas.

Furthermore, this helpful technique can be used to evaluate the students' perception of the provided information by asking them to create their own concept maps/web clusters by means of activating their background schemata, bridging it to the newly-perceived knowledge and making the existing relationships between concepts and ideas more explicit and integrated (Novak \& Cañas, 2006). In addition, the students participate in giving different viewpoints and judgments on authentic tasks by interacting with their prior schemata through understanding how the information content of one sentence links in meaning with the content of the following one (Merkley \& Jeffries, 2000). 
In light of this, students will further make tangible progress in their achievements when lessons are interactive, interesting, and varied. Furthermore, this promising learning setting highlights the necessity for EFL teachers to integrate and implement graphic organisers as visual tools when students are pushed to acquire more understanding about each other, their own self-concept, and the world through the medium of a new language. However, the effectiveness and positive backwash effect of any kind of instruction will be rooted in teachers' constructive skills and knowledge in the development and implementation of graphic organisers (Hutchison \& Padgett, 2007).

It is necessary to note that graphic organisers remove a lot of words involved in prewriting and, through the use of pictures, they force students to make constructive connections among and between the ideas. Figuring out how the piece of writing fits together and flows is the foundation for any good writer. When students can see how ideas are placed into an order, writing is far less frustrating and can actually become something they greatly enjoy doing.

With one diagram, they have all the information they need to know about a particular topic. It can make the learning process a much more enjoyable endeavor for all types of students at all levels. Furthermore, graphic organisers can be implemented while conducting a lecture, no matter whether the class is a large first-year class or a smaller higherlevel course.

Taking into account the students' learning strategies and styles, teachers can use multifaceted graphic organisers in a lecture in different ways for explicit and implicit purposes. First, teachers could use them to prepare their instruction with a more simplified approach. Second, they could use them as a visual aid for students in a large class to guide the talk in a sequence and by topic or in a skill-oriented manner. In teaching reading skills (Merkley \& Jeffries, 2000), graphic organisers allow both the teacher and students to keep an overview of what the topic of discussion is at all times. Moreover, graphic organisers could be used to narrow down many ideas, written in a linear format, into key topics that the teacher would like to discuss in class. Having only the key words or topics that the teachers would like to explain allows the students the freedom to discuss these topics in a structured format without having rehearsed instruction. 
In hindsight, it is crucial to note why graphic organisers are considered as a primary tool for language learning. Graphic organisers resemble networks and allow students to add or alter their background knowledge by seeing the key conceptual connections rather than facts and contradictions between existing knowledge and newly perceived information. Other techniques used to assist students with visualising the general concept and breaking it down into manageable, meaningful, and specific ideas are mind maps or concept maps. As for the incorporation of KWL (Know, Want to Know, Learnt) charts into EFL teaching/learning, this tends to activate students' prior knowledge of a topic or a concept as well as encourage students' active learning, constructive interaction and research skills.

Furthermore, they are helpful and thought-provoking as a pre-reading strategy when reading expository texts, and may also serve as an assessment tool of what students have learnt during a unit of their study. Various implementations of graphic organisers in a reading class make the content area digestion a much more enjoyable and efficient endeavor, as it facilitates students' most complex learning cycles within the content perception in order that they can acquire all of a text's information with its hierarchical arrangements in one graphic organiser. As a result, the students can identify the main ideas and make the desired connections within one diagram. They align all the information-related components and reveal the multilayered interrelationships of various ideas and their logical connections between and among higher and lower order concepts (Alvermann, 1986; Barron, 1979; Hutchinson, 2007).

It is worth mentioning that the explicit purpose of the incorporation of these effective instructional tools in the reading class is to boost students' reading comprehension of the entire meaning of the text by decoding the clues as well as the hidden or directly stated relationships throughout the context. Therefore, while conducting a brainstorming phase to develop a story map, the students reveal their awareness of their current level of understanding and then try to advance themselves. By establishing appropriate scope-related knowledge and pushing their deductive and inductive reasoning skills forward in their minds, students implement various ways of building up enduring understanding. This makes them more autonomous and motivated. 


\section{Graphic Organisers within an e-Portfolio Framework}

There is valuable practice regarding the implementation of graphic organisers within the frame of the e-educational domain, more specifically in an e-portfolio, as one of the most interactive tools to enhance learning and teaching. This can be considered as one of the best platforms for a constructive virtual teacher-student dialogue and students' active participation in multilayer learning through an interactive graphic designer. This is due to the efficient process throughout which the e-portfolio helps to facilitate collaboration and interaction between students and a teacher. It also assists learners in obtaining regular feedback from a teacher through the addition of their comments to individual portfolio items, as well as defining students' weak and strong sides for further learning and improvement.

The aim of the use of the student e-portfolio is to teach and encourage students to organise the flow of their thoughts into further work, to record and learn new vocabulary and to become independent learners. This means that students can be responsible for their own learning by reflecting on it in an e-portfolio domain. It is worth highlighting that in an e-portfolio platform, pre-designed templates of different components are used as a way to scaffold student portfolio activities.

One of the valuable features of using an e-portfolio as an interactive learning and teaching platform is that students may reuse their e-portfolio components (e.g. an academic calendar, a can-do checklist, learning goal statements, reflection forms, self-study and vocabulary logs) throughout their learning journey. They can revisit the same tasks to assess, self-evaluate, make necessary changes according to the comments made by a teacher, and self-reflect at any time. It is evident that time management is an indispensable requirement to be met for any e-portfolio task in order to get a high mark because students have to meet the assigned deadlines for different components.

As a result, graphic organisers incorporated into an e-portfolio domain are intended to assist students in developing their study habits and becoming more autonomous in any learning task. Thus, students learn how to plan their time, find solutions to the problems they have in their study and organise their work effectively, which is why it is important to be aware of their learning styles in any given situation 
and recognise patterns within an e-portfolio framework as well as for them to reflect on their own learning.

\section{Conclusion}

To sum up, regarding the multiple benefits of the use of graphic organisers, they have become a so-called umbrella term containing a range of effective learner-centred tools and instructional strategies that can be applied on a more frequent basis depending on teaching objectives and learning outcomes to be achieved. This may contribute to students' better academic performance on various stages and in different types of formative and summative assessments (Marzano et al., 2001).

Moreover, graphic organisers as described by Drapeau (1998) are aimed at enhancing students' higher-level thinking and cognitive skills by encouraging the process of brainstorming, generating new ideas, aligning them with their background schemata, and classifying, comparing, contrasting, sequencing, synthesising as well as visualising how parts are connected to the whole, which leads to a thorough comprehension of the correlation(s) between ideas, facts and specific operations.

Another tangible benefit of the use of these instructional tools is to support teachers to differentiate a mode of instruction, based on the students' needs and the content being learnt, to understand multilayered concepts (Hall, Kent, McCulley, Davis \& Wanzek, 2013). This will open communication channels among peers and teachers, giving everyone involved a voice.

Encouraging new ways of multiple intelligence is one of the most important advantages of a graphic organiser that has become a vital tool to get students engaged in class activities during which they need an open mindset to think critically about a particular topic based on previously acquired knowledge.

It is believed that not all students are aware of their own learning capacities or know how to foster interaction without being afraid of making mistakes. On the advantages of graphic organisers, Drapeau (1998) emphasizes that they expand students' understanding of divergent complex concepts by visualising general concepts and breaking them down into manageable, tangible and specific ideas. Thus, with the help of the interaction between graphic organisers, 
skill elaboration and active engagement in learning tasks, these tools have become a priority of the educational improvement agenda in the EFL setting.

\section{References}

$\rightarrow$ Alvermann, D. E. (1986). Graphic organisers: Cueing devices for comprehending and remembering main ideas. In: J. F. Baumann (ed.), Teaching main idea comprehension (pp. 210-226). Newark: International Reading Association.

$\rightarrow$ Barron, R. R. (1979). Research for the classroom teacher: Recent developments on the structured overview as an advance organizer. In: H. L. Herbert, J. D. Riley (eds.), Research in reading in the content areas: The fourth report, Syracuse: Syracuse University Reading-Language Arts Center.

$\rightarrow$ Boudah, D. J., Lenz, B. K., Bulgren, J. A., Schumaker J. B. and Deshler, D. D. (2000). Don't water down! Enhance content learning through the unit organizer routine, Teaching Exceptional Children, 3, 48-56.

$\rightarrow$ Boyle, J. R. and Yeager, N. (1997). Blueprints for learning: Using cognitive frameworks for understanding, Teaching Exceptional Children, 29, 26-31.

$\rightarrow$ Bromley, K., Irwin-DeVitis, L. and Modlo, M. (1995). Graphic organisers: Visual strategies for active learning. New York: Scholastic Professional Books.

$\rightarrow$ Cesarone, B. (2007). Concept mapping in early childhood and primary education, Childhood Education, 83, 191-192.

$\rightarrow$ Drapeau, P. (1998). Great teaching with graphic organisers. New York: Scholastic.

$\rightarrow$ Drapeau, P. (2009). Differentiating with Graphic Organisers: Tools to Foster Critical and Creative Thinking. Thousand Oaks: Corwin Press.

$\rightarrow$ Egan, M. (1999). Reflections on effective use of graphic organisers, Journal of Adolescent \& Adult Literacy, 42, 641-645.

$\rightarrow$ Ellis, E. (2004). Q\&A: What's the big deal with graphic organisers?, www. graphicorganisers.com/Sara/ArticlesAbout/Q\&A\%20Graphic\%200rganisers. pdf

$\rightarrow$ Gallavan, N.P. and Kottler, E. (2007). Eight Types of Graphic Organisers for Empowering Social Studies Students and Teachers, Social Studies, 98(3), 117-128.

$\rightarrow$ Hall, C., Kent, S. C., McCulley, L., Davis, A. and Wanzek, J. (2013). A New Look at Mnemonics and Graphic Organisers in the Secondary Social Studies Classroom, Teaching Exceptional Children, 46(1), 47-55.

$\rightarrow$ Hall, T. and Strangman, N. (2002). Graphic organisers. Wakefield: National Center on Accessing the General Curriculum. 
$\rightarrow$ Hutchinson, C. B. and Padgett II, B. L. (2007). How to create and use analogies effectively in teaching science concepts, Science Activities, 44, 69-72.

$\rightarrow$ Marzano, R., Pickering, D. and Pollock, J. (2001). Research-based strategies for increasing student achievement. Classroom instruction that works. Alexandria: Association for Supervision and Curriculum Development.

$\rightarrow$ McKnight, K. S. (2010). The Teacher's Big Book of Graphic Organisers: 100 Reproducible Organisers that Help Kids with Reading, Writing, and the Content Areas. San Francisco: John Wiley \& Sons.

$\rightarrow$ Merkley, D. M. and Jeffries, D. (2000). Guidelines for implementing a graphic orgamar, The Reading Teacher, 54, 350-357.

$\rightarrow$ Novak, J. D. and Cañas, A.J. (2006). The Theory Underlying Concept Maps and How to Construct Them, www.stanford.edu/concept_maps

$\rightarrow$ Williams, J. P. (2005). Instruction in reading comprehension for primary-grade students: A focus on text structure, The Journal of Special Education, 39, 6-18. 